\title{
A Review of Climatic and Vegetation Surveys in Urban Environment with Laser Scanning: a Literature-based Analysis
}

\author{
Zsuzsanna Szabó ${ }^{A}$, Aletta Schlosser ${ }^{A}$, Zoltán Túri ${ }^{A}$, Szilárd Szabó ${ }^{{ }^{*}}$ \\ Received: November 13, 2019 | Revised: December 26, 2019 | Accepted: 30 December 2019 \\ DOI: $10.5937 / g p 23-24675$
}

\begin{abstract}
Laser scanning is a promising relatively new technology of land surveying and has different contributions to research areas and practical applications. We performed a review based on query terms in the Scopus database. We determined the number of papers where the laser scanning was the technique of the survey and refined the results with the aerial (ALS) and terrestrial (TLS) laser scanning methods, and the urban and vegetation searching terms. Results showed that geosciences had a $30-40 \%$ ratio within the scientific papers using LiDAR. TLS had larger relevance related to ALS considering the total number of research papers, urban application and vegetation analysis in urban environment. We analysed the current status of the technology and discussed the underlying possible causes.
\end{abstract}

Keywords: LiDAR; aerial survey; ALS; static survey; terrestrial survey; TLS; Scopus

\section{Introduction}

The modern remote sensing surveying technics such as optical imaging or laser scanning ensure fast and efficient data collection of large areas (Gallay et al., 2013). Laser scanning has a shorter history. Although, the technology was developed in the 1960s, because of the lack of appropriate processing environment (i.e. high-performance computers) and the technological limitations, it was used only in industrial area till the 1990s (Ebrahim, 2016). First practical applications appeared in the early 2000 s, but only became available for a wider scale of users, and became popular in the last 5-15 years due to its decreasing price. However, this technique has a very steep curve of the application in all segments of life (e.g. hydrological modelling, geomorphological analysis, soil and forest mapping, risk analysis, spatial planning and change analysis; (Bal- tensweiler et al., 2017; Gruszczyński et al., 2017; Pirotti et al., 2013; Szczepański et al., 2012) and new fields of usage appear regularly.

Laser scanning is an active type of remote sensing technologies beside the RADAR (radio detection and ranging), but the measuring is based on light detection. Laser beams are emitted (pulses), and their returns (echos) are detected; the measurement itself use the known value of light speed, and the distance will be determined by the time range of the returning beam (divided by two because of the emitted and reflected beams); i.e. it is called light detection and ranging (LiDAR) (Lovas et al., 2012). Equipment can be mounted on different platforms, which discriminates the three main types: static terrestrial laser scanning (TLS), when the equipment is mounted on a moving

\footnotetext{
A Department of Physical Geography and Geoinformatics, University of Debrecen, Egyetem tér 1., Debrecen 4032, Hungary; szabo. zsuzsanna@science.unideb.hu, schlosser.aletta@science.unideb.hu, turi.zoltan@science.unideb.hu, szabo.szilard@science.unideb.hu

* Corresponding author: Szilárd Szabó; email: szabo.szilard@science.unideb.hu
} 
vehicle, mobile laser scanner (MLS), and aerial laser scanning (ALS) (Pfeifer \& Briese, 2007; Vosselman \& Maas, 2010). Each technique has advantages, limitations, and the specific features of data and the requirements of the data preparation and processing is different.

TLS technique is limited by the low scanning angles as the device's height is about $2 \mathrm{~m}$; thus, this perspective foreordains the missing data of tops of trees and buildings (Liang et al., 2018). In spite of large amount of data (25000-1000000 points per second), TLS has the issue by the shadow effect: all surface objects mask the area out behind them similarly to other light types; consequently, important details of the object of interest can be missed, limiting the later applicability of the point cloud (Soudarissanane et al., 2011). It means that a tree will mask out e.g. other trees or buildings, and this effect is more enhanced when the branches and leaves are dense and complex (Marchi et al., 2018). This can be avoided by several TLS scanning position sites from different perspectives (Yang et al., 2016). Besides, the number of returning beams are the function of distance and decrease rapidly from the scanner (Chen et al., 2018). ALS point clouds differ relevantly from the terrestrial scanning: due to higher distance from the scanner (usually 800-2000 $\mathrm{m}$ altitude), laser beams have a footprint on the ground with a diameter of $\sim 20 \mathrm{~cm}$ (Bin et al., 2008). Accordingly, there are more than one returning pulse to the sensor, and although the point density is rather small related to TLS (4-20 points per $\mathrm{m}^{2}$ ), the resulting point cloud can be appropriate for surface evaluation, vegetation analysis or building extraction (Mücke et al., 2013; Priestnall et al., 2000). Beams return from the top of the objects (first return), from the ground (last return) and there can be several returns from the intervening places, usually from the vegetation (Wehr \& Lohr, 1999). In case of ALS, the horizontal and vertical accuracy is lower related to TLS, but large areas can be surveyed within a short time. Besides, ground point classification, and accordingly the digital terrain model (DTM) generation, is easier with ALS data (Baltensweiler et al., 2017; Pirotti et al., 2013). Processing of TLS-based point clouds is a complex task because of the large abundance of the surface objects and their heterogeneous distribution; furthermore, there is no information about the number of returns (Pirotti et al., 2013).

The result of a survey is a point cloud, which can be used to derive a digital terrain model and a digital surface model (DSM). Both digital surfaces is useful and the difference is the normalized digital surface model (nDSM), which shows the relative height of the surface objects. Beside the point cloud, these three terrain layers are the primary input data for object identification or feature extraction (Dong \& Chen, 2018). Urban areas represent a special environment as there are many different types of built-in areas (buildings with varying shape, size and height, roads, pavements) and vegetation (parks with trees and grass and flower gardens); thus, semi-automatic land cover classification can be performed only with large classification error, and the land use categories can only be determined by the experts' decision, individually. LiDAR represents usually auxiliary data for land cover classification, as DTMs or nDSMs can delineate objects (Demir et al., 2008). Buildings can be discriminated from roads and pavements if we can assign a minimum height: a $3 \mathrm{~m}$ relative height combined with a vegetation index (e.g. normalized difference vegetation index, NDVI) gained from optical imaging is a clear difference (Abriha et al., 2018; Szabó et al., 2014). This method also helps to distinguish the low vegetation (i.e. grass) from trees. Using only the point cloud, without optical images, can also be reasonable. Point clouds converted to voxel models can be effective input data even in species identification. Zou et al. (2017) conducted a tree species classification with 93.1-95.6\% overall accuracy using only TLS data and a deep learning model. Furthermore, there are successful applications to retrieve tree data for inventory: diameter of breast height (DBH), basal area, crown base height $(\mathrm{CBH})$, volume or tree height (Kong et al., 2016; Moskal \& Zheng, 2012; Saarinen et al., 2014; Wu et al., 2013).

In this study, we performed a literature analysis from a historical aspect pointing on the breakpoint when the laser technology started to soar. Our aim was to reveal: (i) the role of earth sciences in the laser scanning technology applications, (ii) whether the TLS or ALS techniques are the dominant, (iii) the presence of urban and urban vegetation topics in laser scanning researches.

\section{Data and methodology}

\section{Literature analysis}

We performed a literature analysis using the Scopus (www.scopus.com) scientific document database. We searched for urban and vegetation words as vegetation is a key element in microclimatic analysis in ur- ban environment (Milošević et al., 2017, 2016). Thus, we applied the following searching terms in the article titles, keywords and abstracts:

- "LiDAR" generally,

- "LiDAR" within earth and planetary sciences, 
- "LiDAR” AND “urban”,

- "LiDAR” AND "urban” AND “vegetation”,

- "LiDAR" AND "climate",

- "ALS",

- "ALS” AND "urban",

- "ALS” AND "urban” AND "vegetation",

- "ALS” AND "urban” AND "climate”,

- “TLS",

_ “TLS” AND “urban”,

_ “TLS” AND "urban” AND “vegetation”,

_ “TLS” AND "urban” AND "climate”.

We collected the number of publications altogether by a searching term and by years. Thus, we were able to point on the appearance of a given research area and the breaking point when the research started to increase in a steep curve. This approach has several biasing factors: sometimes the abstract only mentions a searching term, and does not deal with it directly; some papers mention vegetation as green areas; some papers deal with the topic but use different terms for it (e.g. TLS + urban + vegetation can appear as laser scanning + urbanization + green areas). TLS and ALS techniques can be used parallel in the studies, which means redundancy. However, we accepted these limitations because the results confirmed it with number of publications and a more complex query would not mean a better outcome.

\section{Statistical analysis}

We conducted statistical analyses on the number of publications. Trends were identified with comparing the results of different curve fitting methods in PAST 3.26 (Hammer et al., 2001). Break point analysis was used to identify the inflexion point of time series in R. 3.5.3 (R Core Team, 2019) with the strucchange package (Zeileis et al., 2003, 2002). Hypothesis testing was performed to reveal if the differences were different by the query terms in $\mathrm{R}$ 3.5.3 using the ggpubr package (Kassambara, 2019).

\section{Results}

\section{Laser scanning as it is reflected \\ by the number of scientific papers}

Literature search showed that LiDAR technology was used from 1965, but, in this time, it did not mean field surveying, it was used for atmospheric and meteorological research (cloud observation, rainfall, boundary layer or aerosol analysis). Thus, the term of LiDAR in database queries can be a bit of misleading, if we are interested in LiDAR as a surveying tool, but now we also aimed to reveal the meteorological and climatic contributions, too. Number of papers dealing with LiDAR technology followed an exponential trend $\left(\mathrm{R}^{2}=0.93\right.$, Eq. 1), and exceeded 1000 in 2003 , which is also an inflexion point, after that the increase accelerated and reached 4166 in 2018.

$$
y=7.104^{-102} e^{0.118 x}+55.16
$$

It is important to see that how the earth sciences shared its contribution to the laser scanning related researches among the engineering, computer and material sciences. Number of papers also followed exponential trend $\left(\mathrm{R}^{2}=0.94 ; \mathrm{p}<0.001\right.$; Eq. 2$)$, and the inflexion point was in 2006 (Fig. 1).

$$
y=1.952^{-107} e^{0.125 x}+36.38
$$

The ratio of earth science related papers and the total number of papers varied between $4 \%$ to $69 \%$, with a median of $38 \%$. 1990 was a breakpoint as before it the ratio was about $30 \%$ and after this date it reached $40 \%$ (Fig. 2).
Search term of "urban" excluded most papers where the topic used the LiDAR technology as a tool of meteorology (but not all of them because of urban meteorological studies); accordingly, the number of papers relevantly decreased: it was 322 (in 2018) with the search term of "LiDAR and urban". First papers applying LiDAR as survey tool appeared in 1998-1999, before this date the topics of urban aerosol, boundary layer etc. were only in the list, but after 1998 mostly the survey (at first building analysis and then the vegetation) became the focus area. Adding the "vegetation" as further filtering term decreased it to 37 in 2018 and the first studies appeared only in 2003-2004 (Fig. 3).

Database query with ALS and refining the results with "urban" and "vegetation" terms provided a more specific outcome. These papers were published from 1998 rather sporadically, and between 2004 and 2008 the ALS became a stable research topic with relevant content aiming the survey of urban environment. First studies dealt with buildings, but urban vegetation was still a minor topic without a monotonous increasing trend (Fig. 4). Largest number of ALS-papers were published in 2018 (88) but the increase had stopped in the last three years. 2014 was a decrease considering all the 3 types of the groups of papers. But especially papers of the urban vegetation topic's number were rather low, only 2-4, and the maximum was also low, 8 papers.

Considering the TLS technique (Fig. 5), there was a delay related to ALS and the after a slow beginning 


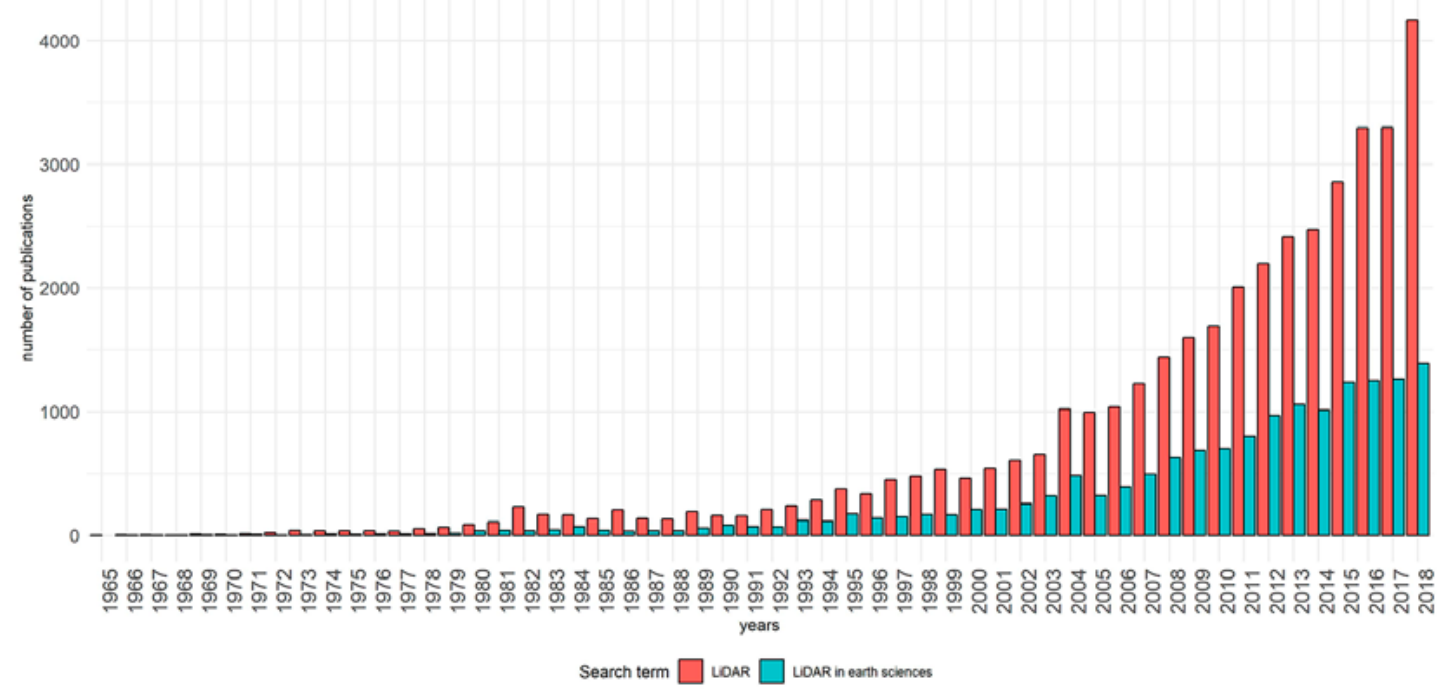

Figure 1. Total number of papers related to LiDAR technology and the subgroup assigned to earth and planetary sciences based on Scopus query

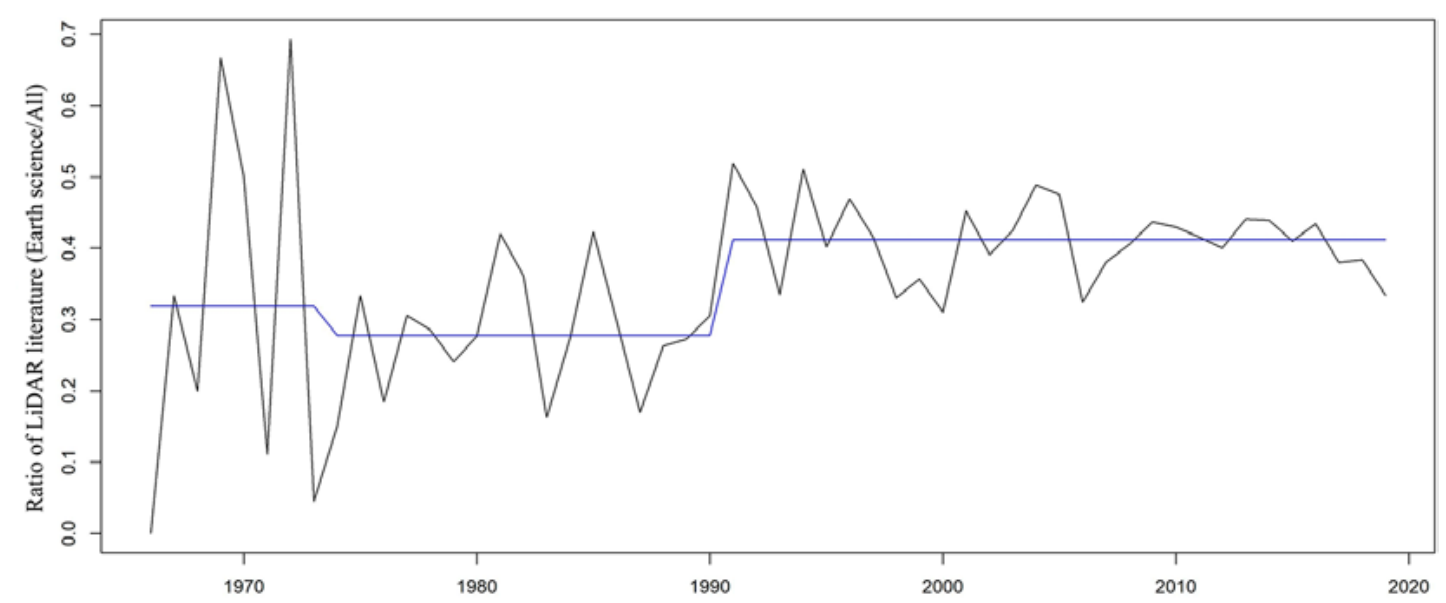

Figure 2. Ratio of papers of earth and planetary sciences and the total number of papers of LiDAR researches based on Scopus query

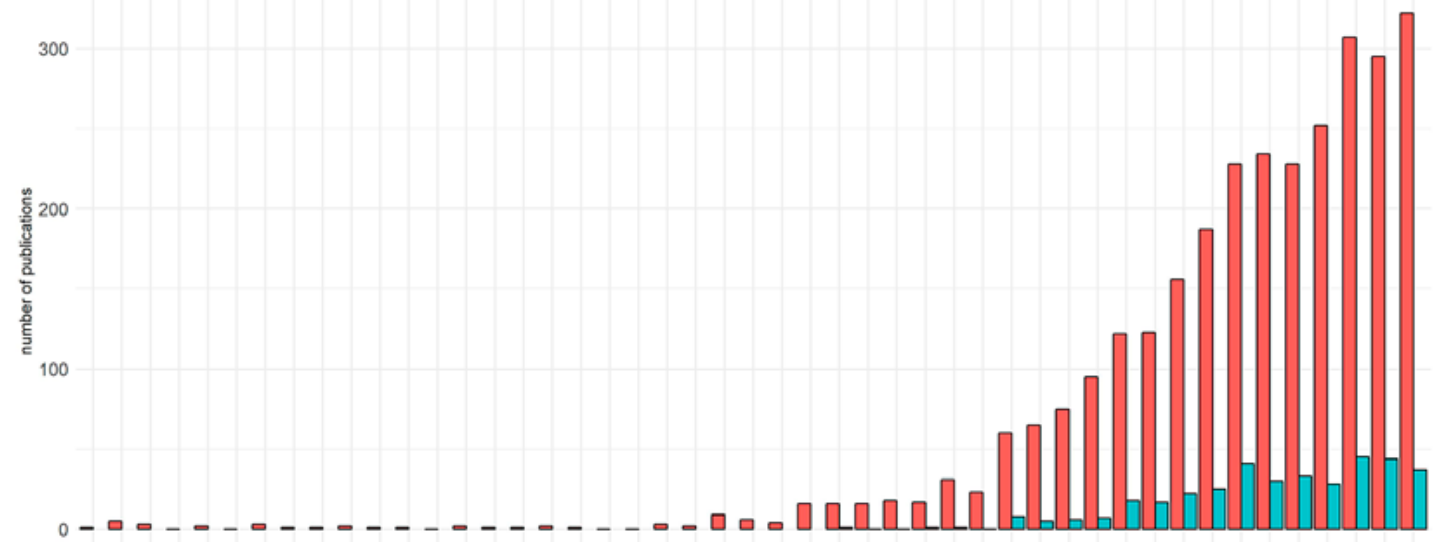

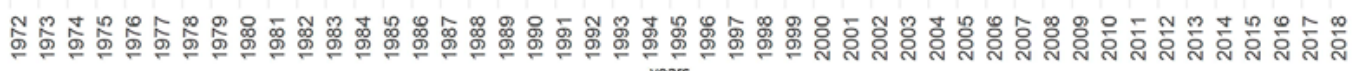
Search term $\square$ LOAR and urban $\square$ LDAR and urtan and vegetatson

Figure 3. Number of LiDAR-based studies in urban environment 


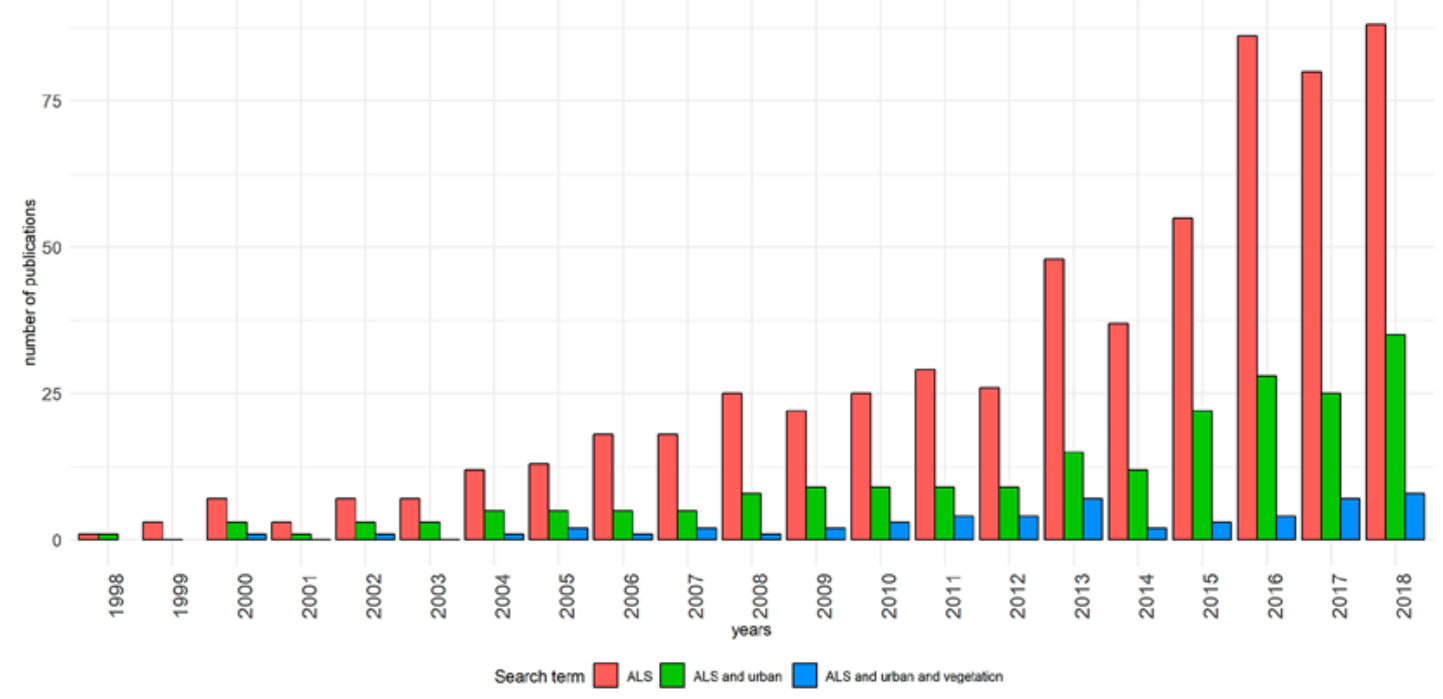

Figure 4. Number of papers dealing with aerial LiDAR scanning (ALS) technique

in 1999, the trend is increasing but unlike the previous queries, this time it followed linear trend $\left(\mathrm{R}^{2}=0.95\right.$, $\mathrm{p}<0.001, \mathrm{Eq} \cdot 3$ ).

$$
y=-30458+15.212 x
$$

Number of publications had a monotonous increasing trend in case of "urban" topics within TLS-studies and it appeared relatively soon, in 2004, after the first applications conducted with TLS. But we had to wait until 2008 to find the first publications dealing with urban vegetation. Both "urban" and "urban and vegetation" related topics have an increasing trend, but while the proportion within TLS was above $20 \%$ for "urban" studies after 2012, the "urban and vegetation" was still very low between $1-7 \%$, without a definite trend, and it was only $4 \%$ even in 2018.

Although there were 129 titles with the search term of "LiDAR" AND "urban" AND "climate", except some real microclimatic studies most of the papers were published in the topic of atmospheric aerosol measured with LiDAR, and not about surveying the environment and using the point cloud to address conclusions.

\section{Comparison of TLS and ALS techniques}

This comparison highlighted the differences both inside the given techniques (i.e. the "urban" and "urban AND vegetation" papers) and between the ALS and TLS (Fig. 6): we revealed significant differences $(\mathrm{p}<0.001$ ), which supported our previous findings that TLS had dominance in the field of laser scanning. It was true in all pairs of paper groups. Considering the total number of papers, there were 610 papers published with ALS and 1971 papers with TLS techniques. Urban related topics represented $34.7 \%$ of ALS and $22.7 \%$ of TLS techniques. The ratio was $8.6 \%$ for ALS and $4.4 \%$ for TLS regarding the researches of vegetation in urban environment.

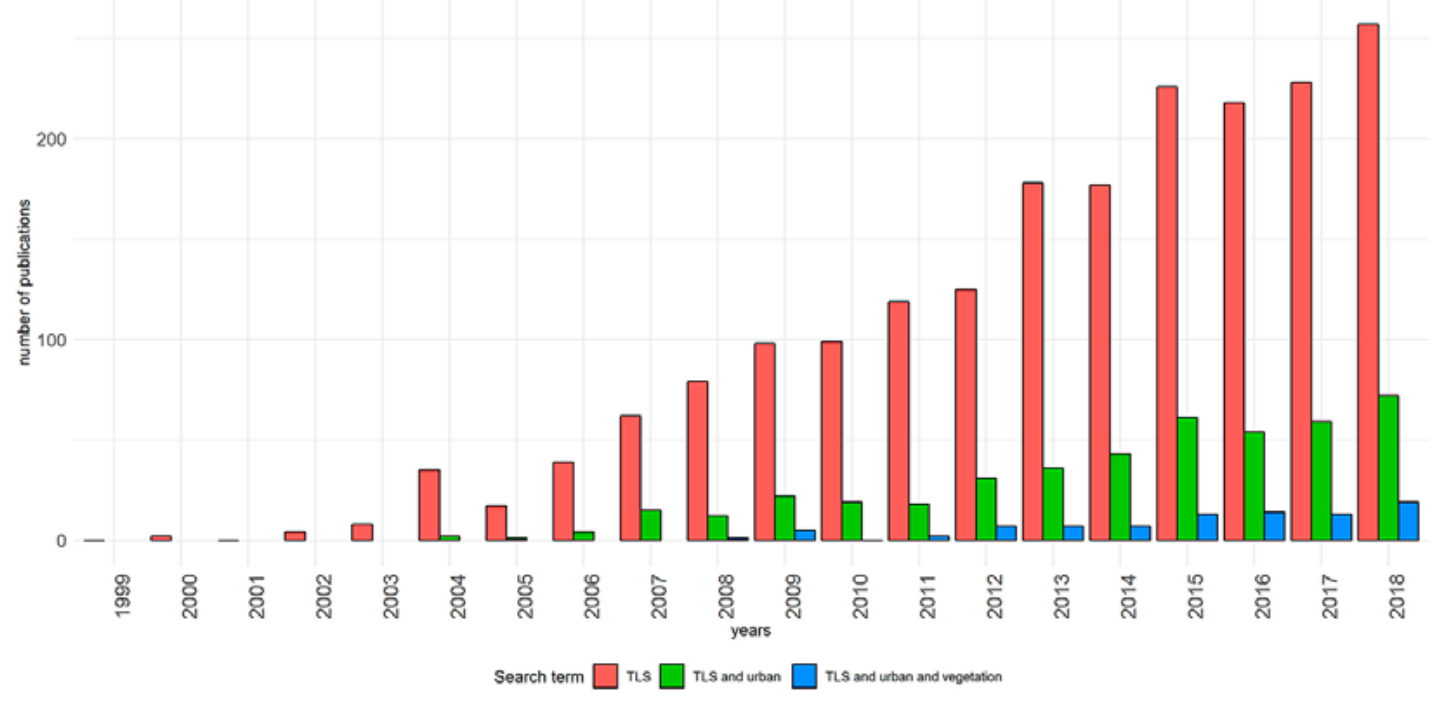

Figure 5. Number of papers dealing with Terrestrial LiDAR Scanning (TLS) technique 


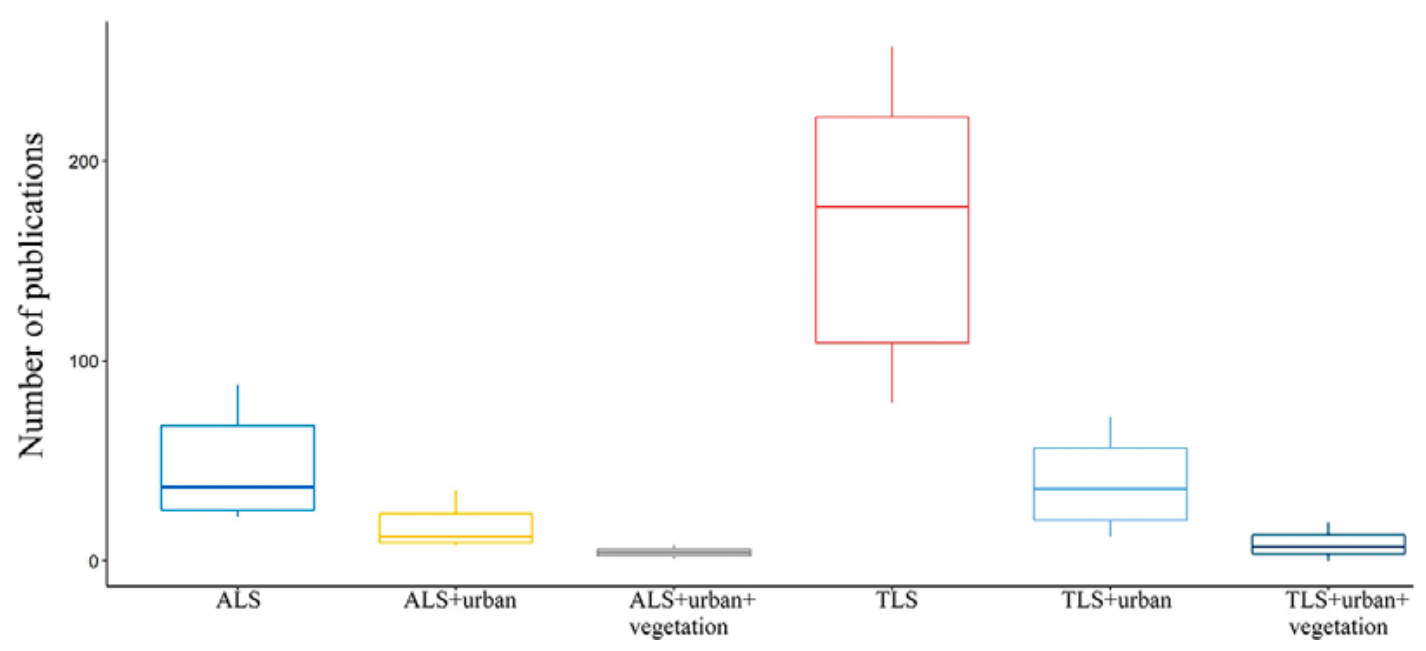

Figure 6. Number of publications in the Scopus database by research areas between 1998 and 2018

\section{Discussion}

Laser scanning undisputedly represents the most developing technology of the early XXIth century. Its history began in 1958 when the theoretical background had been developed and the first ruby-laser appeared in 1960 (Price \& Uren, 1989). Next, it took about ten years to develop the first laser beam based distancemeasuring devices; accordingly, the 1970 s were a period when this technology spread in the industry, and especially surveyors in the USA absorbed it large proportion (Large \& Heritage, 2009). Although there were several reliability issues, the technology became widespread and not only the surveyors, but environmental researches started to use it (Large \& Heritage, 2009). The technology changed from point-based surveys to data clouds (i.e. from total stations with single shots per measurement to automatically scan the complete environment with milliards of data), and from the first laboratory solutions we can find different platforms for terrestrial (static or mobile) and aerial (UAV or airplane) applications. However, this development is not reflected in the number of publications available in the Scopus database, because before the publications the technology had to be known in the industry; furthermore, it had to be affordable for the researchers. After this period, first publications started to report the results, and the method has an exponential increasing trend in the publications from the 1990s, too, but the steep ascendant section began only about 10-15 years ago.

First publications dealt only with meteorological applications such as aerosol, water vapour, boundary layer or wind speed, but this meant micropulse LiDAR based on backscattering (Luo et al., 2014), Raman-LiDAR (Froidevaux et al., 2013), airborne differential absorption LiDAR (Kiemle et al., 1997), Dop-
pler-LiDAR (Banta et al., 2013) or Fibre-based wind LiDAR (Mikkelsen, 2014). LiDAR as a tool of survey in the publications appeared only in the second half of 1990 s when the first robust scanners had been developed and were available in the market. Analysis of the publications means an exact evaluation method of the LiDAR technology, but beside the possible issues raised by the search terms, the real reflection is biased by the types of publications. Large and Heritage (2009) performed a survey and found that between 1999-2004 only $36 \%$ of the results were published in peer-reviewed journals and the rest was found in conference proceedings and in web sites. Accordingly, especially the beginning of our time series (1965-2000) can have some distortion as lots of LiDAR applications were not involved in Scopus. However, Scopus also means a standard as indexes only peer-reviewed journals and conference proceedings; thus, search results can be compared, and the only possible issue is the changes in the publication habits.

Searching with ALS and TLS terms provided a more reliable result, first papers appeared in 1998 in accordance with Large and Heritage (2009). Although ALS had an exponential trend in the increase of scientific papers, and the TLS was "only" linear, the number of papers were significantly ( $\mathrm{p}<0.001,3$-times) larger in case of TLS-based studies. The explanation of this difference can be of several reasons related to the group of users (i) and the costs (ii).

Journals have 1-6 (even more) subject areas, and the same paper can belong to several ones depending on the journal and not the content of the paper. Therefore, it is not possible to express the number of publications in a proportional form, therefore we presented the summed number of papers. According to Table 
1, TLS outperformed the ALS studies. Publications using TLS were at least the double (but in case of environmental sciences it was 30 times more) than those of using ALS. TLS is more often used in geodesy, in engineering, planning and even in historic preservation and virtual reconstruction.

Table 1. Number of publications by subject areas and platforms (based on Scopus)

\begin{tabular}{|l|c|c|}
\hline Subject area & ALS & TLS \\
\hline Computer science & 344 & 763 \\
\hline Engineering & 264 & 692 \\
\hline Earth and computer sciences & 241 & 1006 \\
\hline Social sciences & 180 & 529 \\
\hline Environmental sciences & 11 & 331 \\
\hline
\end{tabular}

ALS ensure surveys of large areas (even $100 \mathrm{~km}^{2}$ or more) but should be mounted on airplanes. There are several technical issues to be solved in the airplane. The mounting itself, to ensure electrical supply, high frequency GPS to record the location in a moving airplane and an inertial measurement unit (IMU) to measure inertia (Lovas et al., 2012). The whole system is expensive, and the maintenance include both the airplane and the ALS-system. Accordingly, this tech- ferent scanning positions should be registered and merged together, which carries the possibility errors. We summed the main characteristics of the two types (aerial and terrestrial) of platforms in Table 2.

Urban studies contribute a relevant part in the application of laser scanning (35\% in ALS, $23 \%$ in TLS papers). ALS technique provides data even for large areas and cities and buildings and vegetation can be extracted from the point clouds. Regarding the buildings usually rooftops and building contours are extracted (Du et al., 2017; Pirasteh et al., 2019; Rybansky et al., 2016; Szabó et al., 2016; Yang et al., 2015). Regarding TLS, urban applications also mean the survey of buildings' interior area with the infrastructure (wires, pipes, etc.) and to arrange the data into a building information modelling (BIM) system. It is a promising section of planning and maintaining buildings aiming to collect data about the geometry, which is the basis of further analysis such as revealing the spatial relations among building elements, cost estimation (e.g. painting, renovation, heating etc.) (Azhar, 2011). Accordingly, engineers and planners also have part in the topic of TLS applications; however, this topic had started only in 2009 and the number of publications is about 6 in a year between 2013-2018. New technologies, such as the new GeoSLAM Zeb-Revo, which op-

Table 2. Comparison of LiDAR survey methods by platform (Baltensweiler et al., 2017; Saarinen et al., 2017)

\begin{tabular}{|l|l|l|}
\hline Subject area & ALS & TLS \\
\hline survey distance & $800-1500 \mathrm{~m}$ & $1-600 \mathrm{~m}$ \\
\hline maximum surveyed area & $\sim 1000 \mathrm{~km}^{2}$ & $\sim 1 \mathrm{~km}^{2}$ \\
\hline data collection & usually $1 \mathrm{flight}$ & $1-100$ scanning positions \\
\hline horizontal accuracy & $\sim 20 \mathrm{~cm}$ & $0.5-2.0 \mathrm{~cm}$ \\
\hline vertical accuracy & $8-50 \mathrm{~cm}$ & $1-2 \mathrm{~cm}$ \\
\hline variation in number of points & varies by land cover density & varies by the distance from scanner \\
\hline number of points & $\begin{array}{l}\text { depends on the scanner capacity, } \\
\text { the settings and the flight altitude: } \\
4-20 \text { points } / \mathrm{m}^{2}\end{array}$ & $\begin{array}{l}\text { depends on the scanner capacity and } \\
\text { the distance from the scanner: } 6400- \\
100000 \text { points/m }\end{array}$ \\
\hline
\end{tabular}

nology is an expensive way of data capturing, nevertheless, one of the most effective and accurate. Users are often just procurers of the surveys and only a few companies can conduct the measurements; thus, the available datasets are limited. In case of TLS, the equipment is also expensive (related to other terrestrial surveying tools such as theodolite, total stations or GPS GNSS devices), but can be affordable for research institutes, universities or even for SMEs (small and medium enterprises). Therefore, once the equipment is purchased and available even each day of the week, more surveys can be conducted with it. The areas surveyed by static TLS are small, and the extent depends on the surveyors, usually is smaller than 100 ha. The accuracy is better than in case of ALS, but dif- erates as a mobile scanner in the surveyor hand can accelerate the application inside the buildings ( $\mathrm{Mu}-$ dicka et al., 2019; Nocerino et al., 2017).

Study of urban vegetation started three years earlier with the ALS technique in 2005 (Ogawa et al., 2005), but due to the cost issues, TLS outpaced it in 2013. We have to note that vegetation in ALS studies often appears as a source of errors in building extractions, because trees covers the building walls and the number of echoes is limited on these sections; i.e. the aim in these papers not to study the vegetation, but to remove them from the point cloud (e.g. Nguyen et al., 2012; $\mathrm{Xu}$ et al., 2012) furthermore, vegetation also covers the ground and as Coveney and Fotheringham (2011) pointed on, it causes errors in ground point classifi- 
cation; therefore, in DTM-generation. Both ALS and TLS are used to determine tree species, and to obtain tree parameters. Koma et al. (2016) and Pyörälä et al. (2019) conducted an investigation on taxonomic classification of five tree species and found that geometric (tree characteristics) and radiometric (spectral features) data made possible to gain $87.5 \%$ overall accuracy. Estornell et al. (2018) found that TLS outperformed ALS in estimating the crown height and pruning biomass, which is the consequence of the lower number of the point cloud in ALS surveys. Especially in case of vegetation, number of points have relevant role in reconstructing individual trees. Accordingly, TLS provides better input data to measure tree parameters.

Trunk diameter (i.e. DBH), crown parameters (length, width, volume), basal canopy area and tree height can be extracted from TLS with good accuracy (Brolly \& Király, 2011; Kankare et al., 2016; Koreň et al., 2017; Liang et al., 2016). The date of survey can also be an important factor (foliage impedes to see the branches; thus, bare trees in late autumn, winter or early spring represent better objects for a detailed analysis).

Finally, there are only a few researches on urban vegetation and microclimate. Kong et al., (2016) performed a TLS-based microclimate survey to reveal the vegetation's cooling effect. Another urban level climatic application was published in 2016, in the topic of microclimatic analysis with a survey of MLS technique in urban environment (Bournez et al., 2016). Both studies pointed on the relevance of LiDAR techniques in urban greenspace planning and how the modern survey methods can help decision makers with exact and accurate information about the builtin areas, and individual buildings; furthermore, vegetation and individual trees. According to quick appearance of new land survey techniques (such as the mentioned GeoSLAM) and the development of microclimatic urban monitoring networks such as the one in Novi Sad (Šećerov et al., 2019, 2015) further developments and achievements can be waited.

\section{Conclusions}

LiDAR technology is a rather new way of surveys, which provides opportunity for object detection and feature extraction through large data clouds. We aimed to reveal the main focus areas of the applications, the relevance of geosciences in the research with laser scanning focusing on urban areas, and the ratio between the terrestrial (TLS) and aerial (ALS) techniques thorough a literature analysis.

We found that LiDAR has about a 50 years history, but the first applications were of meteorological measurements. The first studies were published only from 1998 in the topic of land surveying. Ratio of geosciences papers related to the total number of studies represented a 30-
$40 \%$. Regarding the platform of the equipment, TLS had a larger relevance, exceeding the number of studies using ALS more than three times. The difference in urban applications was only twice larger in case of TLS than ALS. Papers aiming the survey of vegetation in urban areas were 1.5 times higher using TLS techniques, but the proportionally $8 \%$ of ALS and $4 \%$ of TLS surveys dealt with this topic. Although only a few studies were published where laser scanning, urban vegetation and microclimate were the subject of the analysis, an increasing trend can be waited after the current stagnant state. First researches had promising results to help the decision makers to mitigate the hot wave issues of large cities.

\section{Acknowledgement}

The research was funded by the KH 130427 NKFI project.

\section{References}

Abriha, D., Kovács, Z., Ninsawat, S., Bertalan, L., Balázs, B., \& Szabó, S. (2018). Identification of roofing materials with discriminant function analyand random forest classifiers on pan-sharpened worldview-2 imagery - A comparison. Hungarian Geographical Bulletin, 67(4), 375-392. https://doi. org/10.15201/hungeobull.67.4.6
Azhar, S. (2011). Building information modeling (BIM): Trends, benefits, risks, and challenges for the AEC industry. Leadership and Management in Engineering, 11(3), 241-252. https://doi.org/10.1061/ (ASCE)LM.1943-5630.0000127

Baltensweiler, A., Walthert, L., Ginzler, C., Sutter, F., Purves, R. S., \& Hanewinkel, M. (2017). Terrestrial laser scanning improves digital elevation models 
and topsoil $\mathrm{pH}$ modelling in regions with complex topography and dense vegetation. Environmental Modelling and Software, 95, 13-21. https://doi. org/10.1016/j.envsoft.2017.05.009

Banta, R. M., Pichugina, Y. L., Kelley, N. D., Hardesty, R. M., \& Brewer, W. A. (2013). Wind energy meteorology: Insight into wind properties in the turbinerotor layer of the atmosphere from high-resolution doppler lidar. Bulletin of the American Meteorological Society, 94(6), 883-902. https://doi.org/10.1175/ BAMS-D-11-00057.1

Bin, X., Fangfei, L., Keshu, Z., \& Zongjian, L. (2008). Laser footprint size and pointing precision analysis for LiDAR systems. International Archives of the Photogrammetry, Remote Sensing and Spatial Information Sciences - ISPRS Archives, 37 (B1), XXXVII, 331-336. Retrieved from http://www.isprs.org/ proceedings/XXXVII/congress/1_pdf/55.pdf

Bournez, E., Landes, T., Saudreau, M., Kastendeuch, P., \& Najjar, G. (2016). Impact of level of details in the $3 \mathrm{D}$ reconstruction of trees for microclimate modeling. International Archives of the Photogrammetry, Remote Sensing and Spatial Information Sciences - ISPRS Archives, 41(July), 257-264. https://doi. org/10.5194/isprsarchives-XLI-B8-257-2016

Brolly, G., \& Király, G. (2011). Automatizált törzstérképezés földi lézerszkennelés adatainak objektum-orientált feldolgozásával (Automatic stem detection from terrestrial laser scanner data by object-oriented approach). Geomatikai Közlemények, $X I V(1), 139-148$.

Chen, M., Pan, J., \& Xu, J. (2018). Classification of Terrestrial Laser Scanning Data With Density-Adaptive Geometric Features. IEEE Geoscience and Remote Sensing Letters, 15(11), 1795-1799. https://doi. org/10.1109/LGRS.2018.2860589

Coveney, S., \& Fotheringham, S. A. (2011). Terrestrial laser scan error in the presence of dense ground vegetation. Photogrammetric Record, 26(135), 307324. https://doi.org/10.1111/j.1477-9730.2011.00647.x

Demir, N., Poli, D., \& Baltsavias, E. (2008). Extraction of buildings and trees using images and LIDAR data: International Archives of the Photogrammetry, Remote Sensing and Spatial Information Sciences, 37(B4), 313-318. https://doi.org/Export Date 6 May 2013

Dong, P., \& Chen, Q. (2018). LiDAR Remote Sensing and Applications (1st ed.). CRC Press.

Du, S., Zhang, Y., Zou, Z., Xu, S., He, X., \& Chen, S. (2017). Automatic building extraction from LiDAR data fusion of point and grid-based features. ISPRS Journal of Photogrammetry and Remote Sensing, 130, 294-307. https://doi.org/10.1016/j.isprsjprs.2017.06.005
Ebrahim, M. (2016). 3D Laser Scanners: History, Applications and Future. LAP LAMBERT Academic Publishing, (October), 104. https://doi. org/10.13140/2.1.3331.3284

Estornell, J., Velázquez-Martí, B., Fernández-Sarriá, A., \& Martí, J. (2018). Lidar methods for measurement of trees in urban forests. Journal of Applied Remote Sensing, 12(4). https://doi.org/10.1117/1. LRS.12.046009

Froidevaux, M., Higgins, C. W., Simeonov, V., Ristori, P., Pardyjak, E., Serikov, I., Calhoun, R., Van Den Bergh, H., \& Parlange, M. B. (2013). A Raman lidar to measure water vapor in the atmospheric boundary layer. Advances in Water Resources, 51, 345-356. https://doi.org/10.1016/j.advwatres.2012.04.008

Gallay, M., Lloyd, C. D., McKinley, J., \& Barry, L. (2013). Assessing modern ground survey methods and airborne laser scanning for digital terrain modelling: A case study from the Lake District, England. Computers and Geosciences, 51, 216-227. https://doi. org/10.1016/j.cageo.2012.08.015

Gruszczyński, W., Matwij, W., \& Ćwiąkała, P. (2017). Comparison of low-altitude UAV photogrammetry with terrestrial laser scanning as data-source methods for terrain covered in low vegetation. ISPRS Journal of Photogrammetry and Remote Sensing, 126, 168-179. https://doi.org/10.1016/j.isprsjprs.2017.02.015

Hammer, Ø., Harper, D. A. T., \& Ryan, P. D. (2001). Past: Paleontological statistics software package for education and data analysis. Palaeontologia Electronica, 4(1), 1-9.

Kankare, V., Puttonen, E., Holopainen, M., \& Hyyppä, J. (2016). The effect of TLS point cloud sampling on tree detection and diameter measurement accuracy. Remote Sensing Letters, 7(5), 495-502. https:// doi.org/10.1080/2150704X.2016.1157639

Kassambara, A. (2019). $R$ topics documented: Package 'ggpubr .' Retrieved from https://rpkgs.datanovia. com/ggpubr/

Kiemle, C., Ehret, G., Giez, A., Davis, K. J., Lenschow, D. H., \& Oncley, S. P. (1997). Estimation of boundary layer humidity fluxes and statistics from airborne differential absorption lidar (DIAL). Journal of Geophysical Research Atmospheres, 102(24), 29189-29203. https://doi.org/10.1029/97jdo1112

Koma, Z., Koenig, K., \& Höfle, B. (2016). Urban Tree Classification Using Full-Waveform Airborne Laser Scanning. ISPRS Annals of the Photogrammetry, Remote Sensing and Spatial Information Sciences, 3(July), 185-192. https://doi.org/10.5194/isprs-annals-III-3-185-2016

Kong, F., Yan, W., Zheng, G., Yin, H., Cavan, G., Zhan, W., Zhang, N., \& Cheng, L. (2016). Retrieval of threedimensional tree canopy and shade using terrestrial laser scanning (TLS) data to analyze the cooling effect 
of vegetation. Agricultural and Forest Meteorology, 217, 22-34.https://doi.org/10.1016/j.agrformet.2015.11.005

Koreň, M., Mokroš, M., \& Bucha, T. (2017). Accuracy of tree diameter estimation from terrestrial laser scanning by circle-fitting methods. International Journal of Applied Earth Observation and Geoinformation, 63(July), 122-128. https://doi.org/10.1016/j. jag.2017.07.015

Large, A. R. G., \& Heritage, G. L. (2009). Laser Scanning - Evolution of the Discipline. In G. L. Heritage \& A. R. G. Large (Eds.), Laser Scanning for the Environmental Sciences (pp. 1-20). https://doi. org/10.1002/97814443311952.ch1

Liang, X., Hyyppä, J., Kaartinen, H., Lehtomäki, M., Pyörälä, J., Pfeifer, N., Holopainen, M., Brolly, G., Francesco, P., Hackenberg, J., \& Wang, Y. (2018). International benchmarking of terrestrial laser scanning approaches for forest inventories. IS PRS Journal of Photogrammetry and Remote Sensing, 144(July), 137-179. https://doi.org/10.1016/j.isprspiprs.2018.06.021

Liang, X., Kankare, V., Hyyppä, J., Wang, Y., Kukko, A., Haggrén, H., Yu, X., Kaartinen, H., Jaakkola, A., Guan, F., \& Vastaranta, M. (2016). Terrestrial laser scanning in forest inventories. ISPRS Journal of Photogrammetry and Remote Sensing, 115, 63-77. https://doi.org/10.1016/j.isprsiprs.2016.01.006

Lovas, T., Berényi, A., \& Barsi, Á. (2012). Lézerszkennelés (Laser Scanning). Budapest: BME Építőmérnöki Kar Fotogrammetriai és Térinformatikai Tanszék, Terc.

Luo, T., Yuan, R., \& Wang, Z. (2014). Lidar-based remote sensing of atmospheric boundary layer height over land and ocean. Atmospheric Measurement Techniques, 7(1), 173-182. https://doi.org/10.5194/ amt-7-173-2014

Marchi, N., Pirotti, F., \& Lingua, E. (2018). Airborne and terrestrial laser scanning data for the assessment of standing and lying deadwood: Current situation and new perspectives. Remote Sensing, 10(9), 1-21. https://doi.org/10.3390/rs10091356

Mikkelsen, T. (2014). Lidar-based research and innovation at DTU wind energy- A review. Journal of Physics: Conference Series, 524(1). https://doi. org/10.1088/1742-6596/524/1/012007

Milošević, D. D., Bajšanski, I. V., \& Savić, S. M. (2017). Influence of changing trees locations on thermal comfort on street parking lot and footways. Urban Forestry and Urban Greening, 23, 113-124. https:// doi.org/10.1016/j.ufug.2017.03.011

Milošević, D. D., Savić, S. M., Marković, V., Arsenović, D., \& Šećerov, I. (2016). Outdoor human thermal comfort in local climate zones of Novi Sad (Serbia) during heat wave period. Hungarian Geographi- cal Bulletin, 65(2), 129-317. https://doi.org/10.15201/ hungeobull.65.2.4

Moskal, L. M., \& Zheng, G. (2012). Retrieving forest inventory variables with terrestrial laser scanning (TLS) in urban heterogeneous forest. Remote Sensing, 4(1), 1-20. https://doi.org/10.339o/rs4010001

Mücke, W., Deák, B., Schroiff, A., Hollaus, M., \& Pfeifer, N. (2013). Detection of fallen trees in forested areas using small footprint airborne laser scanning data. Canadian Journal of Remote Sensing, 39(SUPPL.1), 32-40. https://doi.org/10.5589/m13-013

Mudicka, S., Matolak, M., \& Kapica, R. (2019). Application of handheld scanner in documentation of historical buildings. 19th International Multidisciplinary Scientific GeoConference SGEM 2019, 39-46. https://doi.org/10.5593/sgem2019/2.2/Sog.006

Nguyen, H. T., Pearce, J. M., Harrap, R., \& Barber, G. (2012). The application of LiDAR to assessment of rooftop solar photovoltaic deployment potential in a municipal district unit. Sensors, 12(4), 4534-4558. https://doi.org/10.3390/s120404534

Nocerino, E., Menna, F., Remondino, F., Toschi, I., \& Rodríguez-Gonzálvez, P. (2017). Investigation of indoor and outdoor performance of two portable mobile mapping systems. Videometrics, Range Imaging, and Applications XIV, 10332, 1-15. https://doi. org/10.1117/12.2270761

Ogawa, K., Endo, T., Tao, G., Yamagishi, Y., \& Yasuoka, Y. (2005). Simulation of $3 \mathrm{D}$ urban landscape with textures and trees by remote sensing. Asian Association on Remote Sensing - 26th Asian Conference on Remote Sensing and 2nd Asian Space Conference, ACRS 2005, 1824-1828. Hanoi, Vietnam.

Pfeifer, N., \& Briese, C. (2007). Geometrical aspects of airborne laser scanning and terrestrial laser scanning. IAPRS, XXXVI(Part3/W52), 311-319. https:// doi.org/10.1007/978-3-319-74748-4 4

Pirasteh, S., Rashidi, P., Rastiveis, H., Huang, S., Zhu, Q., Liu, G., Li, Y., Li, J., \& Seydipour, E. (2019). Developing an algorithm for buildings extraction and determining changes from airborne LiDAR, and comparing with R-CNN method from drone images. Remote Sensing, 11(11), 1-18. https://doi. org $/ 10.3390 / \mathrm{rs} 11111272$

Pirotti, F., Guarnieri, A., \& Vettore, A. (2013). Ground filtering and vegetation mapping using multi-return terrestrial laser scanning. ISPRS Journal of Photogrammetry and Remote Sensing, 76, 56-63. https://doi.org/10.1016/j.isprsjprs.2012.08.003

Price, W. F., \& Uren, J. (1989). PriceWFUrenJ1989_Laser_surveying. Van Nostrand Reinhold (International).

Priestnall, G., Jaafar, J., \& Duncan, A. (2000). Extracting urban features from LiDAR digital surface models. Computers, Environment and Urban 
Systems, 24(2), 65-78. https://doi.org/10.1016/So1989715(99)00047-2

Pyörälä, J., Saarinen, N., Kankare, V., Coops, N. C., Liang, X., Wang, Y., Holopainen, M., Hyyppä, J., \& Vastaranta, M. (2019). Variability of wood properties using airborne and terrestrial laser scanning. Remote Sensing of Environment, 235(October), 1-14. https://doi.org/10.1016/j.rse.2019.111474

R Core Team. (2019). R 3.53 statistical software. Retrieved from https://cran.r-project.org/bin/windows/base/old/3.5.3/

Rybansky, M., Brenova, M., Cermak, J., Van Genderen, J., \& Sivertun. (2016). Vegetation structure determination using LIDAR data and the forest growth parameters. IOP Conference Series: Earth and Environmental Science, 37(1), 1-7. https://doi. org/10.1088/1755-1315/37/1/012031

Saarinen, N., Kankare, V., Vastaranta, M., Luoma, V., Pyörälä, J., Tanhuanpää, T., Liang, X., Kaartinen, H., Kukko, A., Jaakkola, A., \& Hyyppä, J. (2017). Feasibility of Terrestrial laser scanning for collecting stem volume information from single trees. ISPRS Journal of Photogrammetry and Remote Sensing, 123, 140-158. https://doi.org/10.1016/j.isprsjprs.2016.11.012

Saarinen, N., Vastaranta, M., Kankare, V., Tanhuanpää, T., Holopainen, M., Hyyppä, J., \& Hyyppä, H. (2014). Urban-tree-attribute update using multisource single-tree inventory. Forests, 5(5), 1032-1052. https://doi.org/10.3390/f5051032

Šećerov, I. B., Savić, S. M., Milošević, D. D., Arsenović, D. M., Dolinaj, D. M., \& Popov, S. B. (2019). Progressing urban climate research using a high-density monitoring network system. Environmental Monitoring and Assessment, 191(89), 1-19.https:// doi.org/10.1007/s10661-019-7210-0

Šećerov, I., Savić, S., Milošević, D., Marković, V., \& Bajšanski, I. (2015). Development of an automated urban climate monitoring system in Novi Sad (Serbia). Geographica Pannonica, 19(4), 174-183. https:// doi.org/10.5937/GeoPan1504174S

Soudarissanane, S., Lindenbergh, R., Menenti, M., \& Teunissen, P. (2011). Scanning geometry: Influencing factor on the quality of terrestrial laser scanning points. ISPRS Journal of Photogrammetry and Remote Sensing, 66(4), 389-399. https://doi. org/10.1016/j.isprsjprs.2011.01.005

Szabó, S., Burai, P., Kovács, Z., Szabó, G., Kerényi, A., Fazekas, I., Paládi, M., Buday, T., \& Szabó, G. (2014). Testing algorithms for the identification of asbestos roofing based on hyperspectral data. Environmental Engineering and Management Journal, 13(11), 2875-288o. https://doi.org/10.30638/eemj.2014.323
Szabó, S., Enyedi, P., Horváth, M., Kovács, Z., Burai, P., Csoknyai, T., \& Szabó, G. (2016). Automated registration of potential locations for solar energy production with Light Detection and Ranging (LiDAR) and small format photogrammetry. Journal of Cleaner Production, 112(2016), 3820-3829. https:// doi.org/10.1016/j.jclepro.2015.07.117

Szczepański, J., Orczykowski, T., \& Tokarczyk, T. (2012). Using $3 \mathrm{D}$ terrestial laser scanning (TLS) for surveying hydrotechnical structures when preparing flood hazard maps. Polish Journal of Environmental Studies, 21(5), 1405-1412.

Vosselman, G., \& Maas, H.-G. (2010). Airborne and Terrestrial Laser Scanning (1st ed.). CRC Press.

Wehr, A., \& Lohr, U. (1999). Airborne laser scanning - an introduction and overview. ISPRS Journal of Photogrammetry and Remote Sensing, 54, 68-82.

Wu, B., Yu, B., Yue, W., Shu, S., Tan, W., Hu, C., Huang, Y., Wu, J., \& Liu, H. (2013). A voxel-based method for automated identification and morphological parameters estimation of individual street trees from mobile laser scanning data. Remote Sensing, 5(2), 584-611. https://doi.org/10.3390/rs5020584

Xu, S., Oude Elberink, S., \& Vosselman, G. (2012). Entities and features for classification of airborne laser scanning data in urban area. ISPRS Annals of the Photogrammetry, Remote Sensing and Spatial Information Sciences, 1-4(September), 257-262. https:// doi.org/10.5194/isprsannals-I-4-257-2012

Yang, B., Dong, Z., Liang, F., \& Liu, Y. (2016). Automatic registration of large-scale urban scene point clouds based on semantic feature points. ISPRS Journal of Photogrammetry and Remote Sensing, 113, 43-58. https://doi.org/10.1016/j.isprsiprs.2015.12.005

Yang, H., Chen, W., Qian, T., Shen, D., \& Wang, J. (2015). The extraction of vegetation points from LiDAR using $3 \mathrm{D}$ fractal dimension analyses. Remote Sensing, 7(8), 10815-10831. https://doi.org/10.339o/ $\underline{\text { rs70810815 }}$

Zeileis, A., Kleiber, C., Walter, K., \& Hornik, K. (2003). Testing and dating of structural changes in practice. Computational Statistics and Data Analysis, 44(1-2), 109-123. https://doi.org/10.1016/So1679473(03)00030-6

Zeileis, A., Leisch, F., Homik, K., \& Kleiber, C. (2002). strucchange: An R Package for Testing for Structural Change. Journal of Statistical Software, 7(2), $1-38$.

Zou, X., Cheng, M., Wang, C., Xia, Y., \& Li, J. (2017). Tree Classification in Complex Forest Point Clouds Based on Deep Learning. IEEE Geoscience and Remote Sensing Letters, 14(12), 2360-2364. https://doi. org/10.1109/LGRS.2017.2764938 